\title{
ПО ТУ СТОРОНУ «Я»: В ПОИСКАХ НЕВИРТУАЛЬНОЙ РЕАЛЬНОСТИ
}

\begin{abstract}
Аннотация. В данной статье представлена попытка рассмотреть виртуальное пространство как пространство, рожденное на основании декартовского разделения мысленной и протяженной субстаниий. Мысленная субстанция, развернутая наглядными схемами в виртуальном пространстве, показывает, ито она сама представляет собой не более чем зеркало соииального мира. В человеке этот пласт «виртуального» выражен в «я». Известна знаменитая формула Фрейда о том, ито «я» - это Другой. Остается вопрос: что же существует в субъекте помимо этого «я»? Именно в этом «помимо» и кроется непосредственное ощущение реальности. В то же время, если эта реальность остается только неким довеском к субъективности, кантовской вещью в себе, то человек оказывается иеликом во власти внечеловеческого, случайного. В тоже время именно это случайное, чрезвычайное и является основанием для ошущения себя реальным. Реальность оказалась темным пятном потустороннего, она то коренится на дне бессознательного, то, по теории Бадью, сосредоточена в событии как «блуждающем избытке». И в том и другом случае она недоступна человеческой воле, и человек оказывается неспособен выйти за грань самого себя к непосредственности собственного существования. Желание оказыьвается изначально расчлененным структурностью собственного «я», cogito. Его непосредственность, которую Делез называл «вечным двигателем», невозможно осязать вне функиионирующего «я», которое существует как тень, всегда налагающаяся границами на событие жизни, так человек оказывается неспособным вместить событие собственного существования, искажая его в травматических сиеплениях. Но в попытке рассмотреть событие как субъективное и субъекта, как имеющего перспективную возможность ухода от искажений, можно предположить субъективность без «я», субъективность в раскрытии непосредственности желания, выражающегося не через схематизм образа Другого, но через видение себя как Иного, через видение себя как неструктурного Я. Здесь простираются возможности для осознания мистического опыта философов (Соловьева, Булгакова, Трубникова) и прозрений психоаналитиков (Юнга и Лэинга). По ту сторону «я» оказывается безграничная божественная субъективность, которая при этом остается сугубо человеческой.
\end{abstract}

Ключевые слова: психология, киберпространство, виртуальный, я, событие, дуализм, Другой, реальность, желание, Иное.

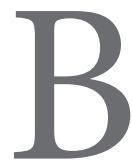

иртуальное пространство создавалось безграничным, почти нематериальным резервуаром ментальных возможностей. Оно стало местом непротяженного отражения мыслящей субстанции. Теперь и телесность памяти перестала быть препятствием для овладения тем, что некогда уже было внесено в область помысленного.

Человеческая протяженность как материальная ограниченность любого механизма, создавала препятствия для нового и нового выстраивания цепочек возможностей. Энергия ментального желания отдавалась окольным путям его осуществления, связанным с телесной ограниченностью, теперь разрыв мыслькоммуникация сократился.

Итак, виртуальное пространство рождалось из экономии. Но помимо экономии, пустота стала складом возможностей, резервуаром желания, а также местомзаместителем, где информация работает за субъект и вместо него.

Киберпространство наиболее удалено от воздействий случайного: биологического, мистического. Оно более всего открыто для понимания функционирующего еgo. Это пространство сознания понятного самому себе, понятного в очевидной прозрачности собственных схем. Cogito вписалось схемами функциональной очевидности в свой производственный, репрезентативный ракурс и только темное, почти звериное осталось в протяженной немой телесности.

Если ничего человеческого нет между телом и cogito, то дальнейшая виртуализация мира становится единственной возможной стратегией человеческого развития. В прозрачности мыслимого желания теряется 


\section{Психология и психотехника 7(58) • 2013}

ощущение реальности, оно оказывается темным пятном нерационализированного остатка действительности. С. Жижек пишет: «Как результат упразднения темной области потустороннего во вселенной современной науки, «глобальная реальность» без этого непроницаемого темного пятна становится чем-то доступным только на экране: устранение иллюзорного экрана, который служил входом в запредельное, превращает всю реальность в то, что «существует только на экране», в двухмерную плоскость. Или, выражаясь онтологическим языком: в тот момент, когда действие темного пятна, которое приоткрывает пространство для чего-то, чему нет места в нашей реальности, устраняется, мы теряем само наше «чувство реальности»». ${ }^{1}$. Это темное пятно между двумя зеркалами: виртуальностью cogito и социумом, возможно, скрывает за собой очевидную непосредственность бытия. В поисках этой недекартовской очевидности мы и развернем свои рассуждения.

\section{1. Человек локальный}

Само новое пространство получило свое рождение из пустоты и не только благодаря техническим средствам. Схема оказалась внедрена в это пространство как его онтологический базис. За границами этой схемы оно не существует, а существует лишь набор устройств по ту сторону интерфейса. Новый резервуар и вовсе не мог бы возникнуть вне структур, ибо он появился извне, а не сам из себя и структуры стали его оболочкой, связывающей новое пространство со своим человеческим отражением. Зеркальность нового пространства стала залогом его существования, и существование стало его заложником.

Сами схемы, как и структуры социума, могут меняться, подстраиваться, но они не устранимы как таковые. Более того в сердцевине они имеют в себе заданные категории, трансцендентальные схемы, схемы языка, которые и образуют его сердцевину, его функциональную гибкость, обеспечивающую множественность степеней свободы. Для примера попробуйте представить себе Facebook без уже обозначенных функций-программ (друзья, хроника, фотографии, подписки и т.д.). Он просто не будет работать. Он существует только через работу схем, в качестве необходимого скелета.

Все возникающие в киберпространстве зоны предназначены к очерченной функциональности. Любая зона оживает за счет репрезентаций. Наполнение ориентировано на выставление чего-то напоказ: информации, социальной позиции, представлений о мире и т.д. Такая заданность предполагает максимальную сродственность

1 Жижек С. Чума фантазий. Х., 2012. С. 278-279. виртуального пространства социуму. Но в отличие от социального мира, здесь невозможно существовать на границе. Здесь всему есть место, даже если это место маргинальное, оно выделено и очерчено, оно не бросается в глаза своей вписанностью в нормальных ход вещей, оно оказывается словно в пузыре огороженности. Маргинал не пройдет перед нами в виртуальном мире как безногий старик в метро.

Виртуальное пространство онтологизирует схемы социума, предоставляя выделенное пространство любой позиции, но выделенное теперь исключает собственную включенность в пространство деятельности. По большому счету в виртуальном пространстве невозможны шизофреники и бомжи. Расщепленное «я» шизофреника существует вне всяких социальных локализаций, оно способно быть всем и ничем одновременно, ему не нужна выделенная ниша для регистрации. Также отсутствие определенного места жительства в виртуальном социуме не способно создать отвратительную вязкость очевидности пограничного существования. В прозрачном мире невозможно быть тем, кем ты не являешься, уходить от собственной определенности в ничто смысла.

Индивид в виртуальном пространстве определяется своей локализацией и своими локальными особенностями, спецификой репрезентации. В отсутствие протяженности, в отсутствие материи, как непосредственного, в виртуальном пространстве оказывается невозможным разрыв, разрыв собственной встроенности в данность системы. Систему не разорвать, не затронув локализации, в ней же зиждется смысловая функциональность индивида. Разрыв возможен только в качестве переворота смысла систем, как их функциональное забалтывание, внедрение вируса или троллинг. Изменения в киберпространстве возможны только через деструкцию ходов означения, деконструкцию программного кода или сталкивание режимов функционирования. При этом ничего кроме порядка означивания не меняется, человек по прежнему остается двухмерным, замкнутым.

Вместимость виртуального пространства стремится к осуществлению возможности неконфликтного взаимодействия в силу безграничности пространственного ресурса, но безграничность одного ресурса лишь усугубляет ограниченность другими. Полнота осуществления самопрезентации здесь невозможна, ибо ментальная территория оказывается всегда ограничена властью означающего разграничения. Так, например, схема популярности, определяет встроенность в заполнение собственного выделенного пространства популярностью и т.д. Существование схемы - определяет наполнение пространства. Так, презентация более 


\section{Философия и психология}

не стремится к индивидуальной реализации, но скорее к занятию наиболее влиятельного места, в котором сходится наибольшее количество локальных координат. Максимальная не-индивидуальность существования на пересечении социальных разломов становится синонимом власти. Влиятельность места сопряжена с присутствием главного означающего системы, при этом личность оказывается интерпретатором, изгибающим линии социального означивания.

Проблема в том, что непротяженное пространства сугубо территориально, еще более территориально, чем пространство протяженное, человек оказывается уже приклеен к своей спецификации, он уже встроен в систему анкетных данных, которые его типологизируют, относят к господствующему означающему. В любых социальных сетях на первом месте пишут место учебы или место работы, затем стандартные характеристики так называемой личности: любимые книги, любимые песни и т.д. Все строится из расчета на другого, которому проще ориентироваться в общении, подбирая нужный типаж или встраивая того или иного человека в определенный контекст существования, не затрагивая само это существование.

Виртуальное пространство создано как некая буферная зона для выплеска всего, что не поместилось в обычной жизни, это мир для реализации, для заполнения фантазиями. Но эти фантазии опять же типологизированы и локализованы. Возможность играть с масками - вот основная характеристика виртуального мира. Здесь нет возможности что-то изменить, это зона для игры. Личность оказывается определенным набором возможностей в рамках стереотипа. Человек оказывается целиком перед лицом себя как видимого, видимое может существовать как таковое только через структурность, и только структура делает видимое возможным.

Социализация происходит на уровне встраивания в социальную машину (мир символического) ${ }^{2}$ через подчинение главному означающему. Но сама форма встраивания всегда скрывает за собой собственное не-бытие собой. Как свидетельствует Лакан: «... символическая форма, как кажется, предшествующая содержанию, появляется при помощи первоначального подавления какого-либо травмирующего ядра «содержания», которое в точности никогда не станет эксплицитным содержанием формы» ${ }^{3}$.

\footnotetext{
2 «Машина - это структура, которая от деятельности субъекта как бы оторвана. Символический мир - это мир машины». (Лакан Ж. «Я» в теории Фрейда и в технике психоанализа (Семинар, Книга II (1954/55)). М., 2009. С. 69).

3 Жижек С. Чума фантазий. Х., 2012. С. 366.
}

Виртуальный мир появился не в качестве дополнения к миру социальному, он ярко выразил в себе присущий современной европейской культуре разрыв формы и содержания. Во многих культурах форма выражала собой существующий миропорядок, в ней отражалось одинаково социальное и религиозное. Мифологические сюжеты пронизывали все предметы быта, все сферы существования, позволяя не останавливаться на однозначности социальной схемы, но видеть также и общезначимые глубокие религиозные смыслы. Вариативность и несколько уровней толкования обеспечивали личностный подход к существующей символической форме. Сегодня формальная сторона внешне-вариативна, но не имеет глубины, и не способна раскрывать личностность, существования оказываются сугубо сингулярными, локальными.

Отсутствие движения овнутрения ${ }^{4}$, являющее человека по ту сторону зеркального мира оказывается ценой прозрачности собственного «я» и понятности его желаний. Желания теперь темны и встроены в процесс искажающего действия травматического события, они более не вливаются в форму, всегда остается неудовлетворенный остаток.

Человек оказывается плоским, ризомным, локальным. Он встроен в горизонт, расширен и обращен к господину желания, к машине-образу социализированного другого.

\section{2. Зачарованность}

Славой Жижек видит причину увлеченности киберпространством в социальной неудовлетворенности и в иллюзорной несхожести открывающегося неисследованного мира 5 .

\footnotetext{
4 «Человек отделен от себя самого всей широтой бытия, которое не есть он. Он заявляет о себе самому себе из другой стороны мира и, овнутряясь, пробивается к себе, ориентируясь на горизонт: человек есть бытие далей. Именно в движении овнутрения, пронизывающем все бытие, бытие возникает и устраивается как мир, не отдавая первенства ни движению над миром, ни миру - над движением. Но это явление себя по ту сторону мира. То есть целостности реального, есть внезапное возникновение «человеческой реальности» в ничто. Только в одном ничто можно подняться над бытием... Случайность мира является в человеческой реальности, поскольку она погружается в ничто, чтобы ее уловить». (Сартр Ж.-П. Бытие и ничто. Опыт феноменологической онтологии. М., 2012. С. 81).

5 «Возможно, именно это вся растущее разочарование в нашем реальном социальном мире является причиной увлеченности, которую вызывает киберпространство: в нем мы словно снова встречаем тот предел, за которым открывается таинственная область иллюзорной несхожести, будто бы экран интерфейса - это современный аналог чистого листа, неисследованной территории». (Жижек С. Чума фантазий. X., 2012. C. 273).
} 


\section{Психология и психотехника 7(58) • 2013}

Первоначальная слабость и неспособность к самоопределению индивида оказываются причиной желания встроиться в мощную, стройную машину виртуального пространства. Разрозненность и неустойчивость субъекта получает свое единство под чарами зачарованности Другим. «В феномене построения Я зачарованность эта играет самую существенную роль. Лишь под этими чарами нескоординированное и несвязное многообразие первоначальной разрозненности получает свое единство. Рефлексия тоже представляет собой зачарованность, торможение» ${ }^{6}$.

Гениальная метафора Лакана, связанная с объяснением формирования «я», как нельзя лучше описывает зеркальную слепоту виртуального образа, метафора о слепом и паралитике или змее и птице. Слепой - тот, кто может двигаться, но не знает куда идти, он несет паралитика. Паралитик зачарован движениями слепого и подчинен его странной власти, он позволяет себя нести. Паралитик, есть наше «я», зачарованное возможностями слепого взгляда. Паралитик лишен своего тела, он есть лишь мыслящая субстанция, протяженность которой есть его обуза и груз, наложенный на видимую гибкость движений. Зачаровывает скоординированность, упорядоченность, возможность влиться в работу социальной машины, с ее динамикой, с ее степенями свободы, с ее отлаженностью производительных движений ${ }^{7}$. Зачаровывает презентация и взаимодействие внутри единой системы, где «я» представлено и существует в виде неотъемлемой части, груза, от которого машина не может избавиться. Взаимодействие осуществляется именно благодаря неосмысленной зачарованности. Она сосредоточена между слепым взглядом и взглядом немощным, между экраном и желанием. Так само личное, собственно субъективное действие оказывается невозможным, ибо в центре между субъектом и образом разлит магнетизм пустоты. Образ действия не присущ субъекту, он вписан в производство, которое дает отнимая. Оно берет на себя как груз субъективность, чтобы стать наполненным иллюзией осмысленности.

Действия и возможности оказываются смыслом существования нашего «я». При этом сам смысл порожден этими внешними возможностями, возможностями, которым не мы придали смысл. Парадокс заключается в том, что желания и возможности по своей форме никогда не могут совпасть: «...Я, всецело определяемое

6 Лакан Ж. «Я» в теории Фрейда и в технике психоанализа (Семинар, Книга II (1954/55)). М., 2009. С. 74.

7 «Движение каждой машины обусловлено, таким образом, восприятием определенной стадии, достигнутой другой машиной. Это как раз и есть то, что соответствует элементу зачарованности». (Там же. С. 75). формой единства другого Я, принципиально несовместимо с ним в плане желания» ${ }^{8}$. Желание оказывается парализованным, кастрированным, отделенным от своего собственного осуществления. Желание становится нехваткой.

Единственно возможным выходом оказывается падение. Падение разрывает зачарованность, отстыковывает субъект от своего «я». Падение уходит от рефлексии, как воспроизводства связи. Оно создает область вне связности, вне необходимости кастрации. В этой области уже нет более смысла, она разрушает смысл как произведенное, производственное осуществление, коэффициент полезного действия которого оставляет за реальностью лишь излишки тепловой энергии.

Машина - есть символ вписанного существования, символ того, чего в нем нет, меня как отсутствующего. «Машина реализует непрерывность, благодаря которой люди, какое-то время отсутствовавшие, получают в свое распоряжение регистрацию того, что произошло в интервале между феноменами сознания в собственном смысле» ${ }^{9}$.

Зачаровывает то, что механизм есть именно коррелят абсолютной реальности. Он делает реальным. Существование в социальной сети делает реальными мои переживания в пространстве, которое оказывается более объективным, нежели невиртуальное пространство. Виртуально-локализованное «я» становится нашей наружей, улицей, куда выходят наши окна. Внутри же остается необжитое пространство со своими темными углами. Виртуальное «я» работает за меня в отсутствии моей координации, несет к своим невидимым далям.

Машина - это способ существования, это зеркало, которое позволяет отражать стимулы и реакции мира. Зеркало как в «Менинах» Веласкеса не отражает субъекта, не отражает взгляд смотрящего на картину, оно отражает только взгляд господина, взгляд заказчика, взгляд внешнего «ради». Смысл существования «я» в том, что оно может быть только исполнителем, машиной существующей перед собственной пустотой и видимой властью Другого. «Я» порождает пространство между несубъективным желанием и его реализацией. «Я» это зеркальная машина исполнения, серя сторона холста, благодаря которой аккумулируется напряжение между существующими объектными структурами. Желание становится лишь ватой, их наполнителем. «Я» это проводник желания, то, что распихивает его по пространству между объектами. «Я» осуществляет, прежде всего, связь желаемого, его презентацию. «Я»

\footnotetext{
8 Там же. С. 75.

9 Там же. С. 69.
} 


\section{Философия и психология}

всегда заворожено собственной пустотой и волей распорядителя, оно стремится быть серым холстом, зеркалом, встроенным в рождающееся мирозаполнение. Виртуальный мир - это огромное «Я» человечества, зеркало, чарующее пустотой слепого взгляда и властностью означающего.

Если мир оставить без «я», лишь с голым рационализмом cogito, с его бесконечными разделительными линиями, поверх живого существования, то само бытие распадется, не будучи скрепленным связями желания, не будучи вовлеченным в эти связи. Тогда все по-сартровски становится отдельным, расчлененным, отстраненным и тошнотворным бытием реального, бытием субъекта разделяющего и ничтожащего, субъекта как ничто.

Воображение создает мир человеческого, и «я» оказывается призмой воображения, фильтром, через который энергия желания проходит и выдает сознанию конкретные образы желаемого. «Я» при этом всегда другой. Сама призма «я» ограничивает желание, делая его топографичным, расчерчивая по карте главного означающего.

\section{3. Вирус как точка реальности}

Реальность это точка, которая травмирует все изображение, оно близится к искажению, но границы искажения указывают на реальность, не открывая ее. Искажение - это случайность, которая вдруг рушит всю систему, но эта случайность и была изначальной, как изначальная невозможность.

Начало единства «я» открывается из черной точки. Вирус есть точка реальности виртуального пространства, тот травматический элемент, который оказывается всегда в невидимом центре. Травма собственно заключена в возвращении в состояние нестабильности, в состояние невстроенности в систему. Вирус - есть безосновное свидетельство о реальности невиртуального, это страх жизни, извечно присущий существованию, страх самой невозможности более быть встроенным, быть машиной, быть частью, страх потери несущего образа.

Отсутствие возможностей - это и есть вирус, внезапное спутывание рационального и превращение в нерациональное, бессмысленное. Без вируса виртуальный мир становится машиной символического работающей за субъекта, машиной, которая вполне может существовать и без него.

Вирус - это невозможность больше быть другим, это раскрытие разрушительной силы другого. Вирус как грех Адама, в котором больше не отражаются бог и человек. Он создает точку реальности, как точку искажающего события, в котором больше нет ничего кроме падения.

Мир в падении, мир без «я» оказывается странным пространством между двумя зеркалами, пространством в котором и заключена реальность. Вопрос в том, что это пространство пусто. В центре оказывается точка, из которой возникают отражения, но она пустая, в ней ничего нет, в ней мы сами, которые себя не видим, потому как смотрим только на отражения зеркала в зеркале, мы смотрим из одного зеркала на другое и не можем увидеть ничего кроме зеркала, ибо нашим взглядом является отражение.

Есть ли что-то за гранью вируса, что говорит нам о существовании неиллюзорной подлинности? Все крутится и кружится, все остается в пространстве бесконечных повторений, в пространстве вокруг и около реальности, но ее никогда не касается. Все даже, может быть, самые яркие озарения овеяны напряжением разлитого желания, которое и становится единственным ощущением собственного присутствия. Но желание здесь знает себя только через собственную ограниченность в «я». «Я» - это граница желания.

Продуктивность «я», все его функционирование есть лишь отражение одного и того же, тождество бытия и мышления (неважно мышление накладывается на бытие или бытие определяет сознание, мы всегда оказываемся зеркальными). При этом в зеркальности всегда происходит ускользание от события реального, лишь в размыкании этого тождества и можно ощутить непосредственную реальность как процесс.

Необходимо продвижение, вечное разрывающее связи падение, чтобы вырваться из локальной зеркальности. Движение возможно в проникновении за фактичность травматического события и расчерченность возможного осознания желания к его непосредственности. Сегодня точка реального оказывается между двумя экранами: между мной как сингулярностью и социальным миром, как машиной означивания. И весь соблазн виртуальности заключается в том, что на этом месте может не оказаться разрыва.

\section{4. Танец в темноте}

Без образа в зеркале, без «я» желание вырывается в абсурдность танца в темноте. Танец в темноте - это самопроизвольные движения желания, которые вдруг становятся самозначимыми, они более не зависят от социального и культурного бытия. Они теперь всегда есть ценность как таковая. Она видна тому, кто что-то делает, более не ожидая явления совершенства извне. Ценность заключена в темноте его самого. Она больше не высится на пьедестале господствующего, больше не 


\section{Психология и психотехника 7(58) • 2013}

встроена в традицию, не требует поклонения, она есть вспышка света, который всегда очевиден.

Танцы в темноте - это чрезмерность без образа, слепая завороженность, которая рождает тепловую энергию без производства. Эта энергия не имеет в себе образности. Это крушение образа. Собственная бессмысленность заставляет двигаться без направления. Это движение есть танец в темноте, где движения становятся воплощением чрезмерности. Они становятся лишним паром для машины социума, но только из этого пара и рождается ощущение реальности.

\section{5. Чрезмерность}

Травматичное событие, к раскрытию которого стремится психоанализ, не вполне раскрывает причины ограниченности желания. Травма как провал лишь обозначает зеркальные границы существования, но не указывает на их преодоление. Но само событие оказывается здесь не только указателем на межи желания, оно центрирует движение, которое способно вырваться за границы фактичности события. Если, как пишет Бадью, событие оказывается собственно тем самым неразличимым, из чего рождается любой разрыв, то оно вообще не может быть встроено в историю, оно оказывается вне-исторично. Оно неспособно цепляться ни за какие связи, оно упраздняет их, заставляя все кружиться вокруг этой изначальной неразрешимости.

Событие, которое у Лакана трактуется как травма, все же имеет нечто и вне своей травматичности. Собственно травма открывает то, что является темным пятном, которого не видит рациональный дискурс субъекта. Это пятно и создает изначальную неразличимость. Оно и есть тень собственного «я». Именно «я» заслоняет собой реальный момент, который потому и становится травмой, что он невозможен для видения. Травма есть лишь то, что скрывает от человека реальность, она есть искажение. Так, искажающим оказывается собственно «я» субъекта, которое и образует поверхность зеркала, образует образы, которые уже намечаются в его отображении, при этом сама реальность совершенно не видна. Она спрятана за тем, что не способно ее разглядеть, по ту сторону травматичного момента.

В самом «я» невозможно событие, также как оно невозможно в виртуальном мире. Он ограничен лишь присутствием. Сегодня в нем прочитывается принципиальная дуальность субъекта и образа, вещи и идеи. Субъект - это вещь и она бессмысленна без образа, который ее означивает и одухотворяет, «я» оказывается для субъекта образом, все остальное может присутствовать лишь по ту сторону понимания, в чрезмерности.
В событии всегда оказывается что-то, чего не может увидеть субъект, некое его собственное преодоление.

Поиски родовых начал философии привели Алана Бадью к событию как чрезмерности ${ }^{10}$, как той случайной избыточности по отношению к мысли, из которой она и могла только родиться. Избыток и оказывается истинно реальным, но при этом он лишается мысли, он есть случайность. «Именно в этом реальном пункте блуждающем избытке в бесконечном количестве - и основываются великие ориентации мысли» ${ }^{11}$.

Избыток часто и мыслится как истинно-реальное. Избыток в науке и есть то самое реальное, что оказывает сопротивление теории, теория есть то, что выверено и поставлено в своей зеркальности именно перед избытком, как своим реальным, избыток есть то, на чем собственно и основывается продвижение науки.

Бытие есть чрезмерность сущего, сакральное есть чрезмерность профанного, факт есть чрезмерность истории.

Объяснение нерациональных вещей кажется задачей философии, кажется способом овладеть жизнью. Но именно в этом способе само реальное всегда оказывается во вне, всегда тенью процесса означивания. Тень всегда остается недоступной, и в этом вечном ускользании, в вечной завороженности самим процессом отражения, происходит существование.

10 «Истинностные процедуры, или процедуры родовые, отличаются от накопления знаний своим событийным происхождением. Пока случается только то, что соответствует правилам некоего положения вещей, возможно, конечно же, познание, правильные высказывания, накопление знаний; невозможна здесь истина. Истина парадоксальна тем, что она одновременно и внове, следовательно,- нечто редкостное, исключительное, и, затрагивая само бытие того, истиной чего является, наиболее прочна, наиболее, говоря онтологически, близка к исходному положению вещей». (Бадью Ален. Манифест философии / сост. и пер. с франц. В.Е. Лапицкого. СПб.: Machina, 2003 [электронный ресурс - www.artinfo.ru/ru/news/ main/Alain_Badiou-manifeste_pour_la_philosophie.htm].

11 Для разворачивания относящейся к ситуации истинностной процедуры необходимо, чтобы эту ситуацию пополнило некое чистое событие. Это пополнение оказывается неименуемым, не представимым ресурсами самой ситуации (ее структурой, установленным для называния ее терминов языком и т.д.). Оно вносится особым именованием, запуском сверх того еще одного означающего. Именно последствия ввода в игру в данной ситуации еще одного имени и запускают родовую процедуру, вносят предвкушение истины этой ситуации. Ибо изначально в ситуации, если ее не дополняет какое-либо событие, нет никакой истины. В ней есть только то, что я зову правдоподобием. По диагонали, походя, из всех правдоподобных высказываний - всегда есть шанс, что явится истина, стоит какому-либо событию столкнуться со своим избыточным именем. (Там же). 


\section{Философия и психология}

\begin{abstract}
Чрезмерное оказывается тем самым непроницаемым темным пятном, которое в основе всего, но которое невозможно увидеть. Это темное пятно оказывается тенью «я» и сопряжено с желанием. «Я» способно существовать только в своей событийной чрезмерности. Чрезмерности вырываются из образа, как его вечная неоконченность. Неразличенное в пропасти между субъектом и объектом, то, что их формирует, что становится их условием, и является самой чрезмерностью. Но неразличенность при этом оказывается непроникновенной. Она нечеловечна, несубъективна. Здесь Бадью в духе Канта оставляет истину за границей человеческого постижения, неким условием мысли, условием философии, и, по сути, условием человечности. Здесь субъект понимается в своей прозрачной видимости, а потому невидимое остается за гранью субъекта. Слепая Ананке снова взмывает над человеком, вцепляясь в него своим слепым взглядом ${ }^{12}$.
\end{abstract}

Мы смотрим на солнце, только тогда, когда наша собственная земная тень закрывает солнечный диск. Избыточность может быть непосредственным, как вещь в себе, она невидима. Именно избыточность и является, по сути, наиболее субъективной, она действует как судьба, она есть именно то, что оказывается непонятным, но это непонятное и требует объяснения. Ход Бадью останавливает нас на смирении перед множественностью избыточных истин, он ставит перед философией условия ее существования, вне которых она уже ни на что не способна. Мысль оказывается зависимой от случайных событий, уже немыслимых. Тогда зачем нужна мысль, если она неспособна помыслить то, что лежит в основании, разве не об основаниях всегда думала философия?

Избыточность множественностей сама способна существовать, если есть что-то, что способно уловить эту множественность сверху. Для немецких идеалистов,

12 «Если истина образует дыру в знании, если тем самым не бывает знания истины, а бывает лишь производство истин, то дело тут в том, что продуманная в своем бытии математической (то есть как чистая множественность) истина является родовой, избегающей всякого точного обозначения, избыточной по отношению к тому, что оное позволяет различить. Цена, которую надо платить за эту убежденность, состоит в том, что количество множественности претерпевает неопределенность, своего рода дефект разделительности, который и наделяет полнотой реальности само бытие: просто-напросто невозможно осмыслить количественное соотношение между «числом» элементов бесконечного множества и числом его частей. Это соотношение имеет форму лишь блуждающего избытка: известно, что части более многочисленны, нежели элементы (теорема Кантора), но не представляется возможным установить какую-либо меру этого «более». Впрочем, именно на этом реальном пункте блуждающем избытке в бесконечном количестве - и основываются великие ориентации мысли». (Там же). экзистенциалистов и других - этим нечто был субъект. Убирая субъект, мы оставляем множественность, но эта множественность невидима, она остается в случайности приходящего события, приходящего откуда-то, просто происходящего, случающегося. Но это событие остается невозможным в качестве реальности, потому как в нем не оказывается места человеческому желанию, оно становится избыточным местом в пространстве человеческого, местом по ту сторону экрана.

У экзистенциалистов избыточность появляется как некий ужас бытия, граница, раскрывающая смыслы существования, боль, смерть, то, что выходит за рамки рассудка и кажется невозможным для осмысления и тогда бытие представало как бы изнутри этой границы, оно оказывалось субъективностью, которая шла сама к себе через избыточность, которая и открывала ей себя.

Попытки разглядеть истину бытия через ограничение, экзистенциалы, которые указывали на реальность, на бытие как таковое, грешили тем, что граница субъекта оказывалась единственно возможным способом видеть непосредственное. Искажения, указывающие на сокрытое, воспринимались как указывающие на реальность саму по себе. Так искажения становились орудием видения субъекта, в них просматривалась травма и слепое пятно «я», которое и позволяет видеть событие как лишь как травматическое.

Событие оказывается возможным к рассмотрению через процесс ужатия «я», кенозис. Боль, смерть и болезнь, рассмотренные экзистенциалистами, могут ломать структуры «я», и указывать на глубокие пласты основания субъекта, но они сами не могут становиться при этом чем-то абсолютно существующим и основанием любого человеческого существования, за гранью травматического события лежит субъект вне травмы, прошедший сквозь травматическое искажение.

\section{6. Симулякр}

Чрезмерность как подоснова мысли открывает перед нами бытие симулякров, которые, как говорил Бодрийяр, и являют собой саму реальность. Симулякры оказываются той самой чрезмерностью, которая более всего и указывает на субъект. Именно поэтому они даже более реальны иногда, чем реальность. Более того, виртуальный мир весь состоит из симулятивных чрезмерностей. Они часто острее передают те или иные чувства. Подобная чрезмерность, служит основанием для проигрывания желаний и фантазий, для игры в жизнь как нечто более ощутимое. Здесь чрезмерности оказываются извращениями, которые опять 


\section{Психология и психотехника 7(58) • 2013}

же указывают на «я». Для Лакана «я» ${ }^{13}-$ это другой и за машиной производства, машиной, где человек наследует травматичные сцепления своих предков, ничего нет. Событие не являет настоящее Я или нечто скрытое за экраном образа. Паралитик невозможен без слепого. Целостность человека достигается через встраеваемость в общую машину, но в опыте целостность дается как твое личное событие, как неискаженная граница, самоограничение и свобода самого себя. Я, как собственное иное, в событии присутствует как очевидность. Т.е. само Я манифестирует событие. Но в то же время «я», как тождественное, есть тень, которая откладывается на событии и увидеть его как таковое невозможно. Сама очевидность субъективна, но не из субъекта, она то, чем мог бы быть субъект без «я» - то есть в непосредственности желания.

В шизофрении при расщеплении «я», при удалении операциональности этого «я», часто открываются странные прозрения и возможности быть всем ${ }^{14}$. Событие всегда разжимает «я», оно есть его завершение и всевозможность. Событие всегда ускользает потому, что также встраивается в действительность как цепочку. И теряет свою целостность.

Избыточность не может быть ни чисто объективной, тогда она становится непознаваемой вещью в себе, и тогда она просто невозможность. Не может она и присутствовать в прозрачном cogito. Избыточность существует только в непосредственности желания, существующего вне субъект-объектного разделения.

Событие также не может быть лишь индивидуальным сцеплением, травмой, в нем и слом прежних структур «я» и зияние внеструктурного субъекта, Я.

\section{7. По ту сторону «я»}

Р. Лэинг и К.Г. Юнг видели основание целостности субъекта по ту сторону внешнего, социального образа. Юнг, описывая коллективное бессознательное, видит образ Анимы, в качестве центрирующего субъект фактора в глубине его самого ${ }^{15}$. Анима оказывается формой,

13 Собственное «я» человека у Лакана обозначено как Я.

14 Р. Лэинг описывает так описывает опыт одной своей пациентки с диагнозом шизофрения: «Реальность не бросала свою тень или свой свет на ее желания или страхи. Каждое желание встречало мгновенное фантастическое выполнение, а каждый страх точно так же мгновенно фантастическим образом исчезал. Таким образом, она могла быть кем угодно, где угодно и когда угодно». (Лэинг Р. Расколотое «я». СПб., 1995. C. 220).

15 «Анима - это не душа догматов, не anima rationalis т.e. философское понятие, но природный архетип. Только он способен удовлетворительным образом свести едино все в которую вливаются содержания культуры, она делает их вместимыми в конкретное сознание.

Р. Лэинг также подходил к рассматриванию человека за границами его «я». Рассматривая шизофреников, для которых их собственное «я» давно стало фантомным, он находит веру и проявления некоего внутреннего центрирующего основания в субъекте ${ }^{16}$.

Важной традицией подобного осмысления является отечественная софилогия в лице таких философов как Владимир Соловьев, Сергей Булгаков и Павел Флоренский. София. Представленная Соловьевым как Душа Мира, Вечная Женственность, увиденная Булгаковым как Сущность Божественная и человеческая, открывает существование человеческой субъективности вне «я», при этом эта субъективность не является Богом, но она божественна.

Рассмотрение подсознательного и чрезвычайного опыта человеческой психики напрямую подводит к поискам субъективности по ту сторону «я». Рассматривая мистические прозрения русских философов: В. Соловьева, С. Булгакова, Н. Трубникова ${ }^{17}$ можно выделить несколько обобщающих характеристик:

Во-первых, акт прозрения и встречи с божественным образом является всегда событием, конкретным и неожиданным, во вторых - это событие связано с преображением самого субъекта, видением им некоего иного Я. Событие вносит раскол в субъект, за травмой открывается то наше я, которое было до этого невидимым, то, что явилось уже не столько, как всего лишь наше я, сколько как всеобъемлющая божественность самой возможности существования этого я.

Черная точка между двух зеркал оказывается лишь нашей слепотой.

проявления бессознательного, примитивных духов, историю языка и религии. Анима - это «фактор» в подлинном смысле этого слова. С нею ничего нельзя поделать; она всегда есть а priori настроений, реакций, импульсов, всего того, что психически спонтанно. Она живет из самой себя и делает нас живущими. Это жизнь над сознанием, которое не способно ее интегрировать - напротив, оно всегда проистекает из жизни». (Юнг К.Г. Архетип и символ [электронный ресурс www.koob.ru/jung/arhetip_i_simvol]).

16 «...она оценивала себя только в виде фантома. Существовала вера в то, что есть нечто очень ценное, потерянное или спрятанное глубоко внутри нее и пока не найденное ни ею самой, ни кем-либо другим». (Лэинг Р. Расколотое «я». СПб., 1995. С. 222).

17 См. статью: Глинчикова Е.В. В прозрачности «Светлого Божества» (о возможности экзистенциальной интерпретации мистического опыта на примере произведения Н.Н. Трубникова «Зефи, светлое мое Божество, или после заседания (из записок покойного К.)») // Филология: научные исследования. 2013. № 1 (09). C. 43-48. 


\section{Философия и психология}

Существование человека в пространстве до события, есть существование в пространстве неоформленности, в пространстве где, человек не имеет оси, на которую он мог бы нанизать себя, той оси, которая сделала бы центрированным все его желания. Ось сбора желания называется ограничением. Так вот это ограничение должно быть очевидным, оно должно быть наглядным и гарантированным. То есть это та форма, в которую вливается все содержание желания, ось напряжения, которая становится видимой, указывает на вину как раскол между «я» и Я. На этой оси нет уже «я» как субъекта, как машины встроенной в общую машинерию социального. Остается событие и форма идеального существования, в которую вкладывается все многообразие опыта. Тогда именно и становится возможным для человека проникнуть за оболочку искажения, перестать быть встроенным. Цельность, которая достижима в культуре только через встраиваемость, через свое развитие и завершение в опыте другого имеет в себе логику тоталитаризма, во главе становится программист, создатель программ или программист, который внедряет вирусы, бог и дьявол, но существующие в отражениях. Точка реальности есть точка события небытия и точка события боговоплощения. Воплощение для человека своего существа возможно только в точке реальности. Там только и может существовать и сам Бог и человек.

\section{Список литературь:}

1. Бадью Ален. Манифест философии / сост. и пер. с франц. В.Е. Лапицкого. СПб.: Machina, 2003.

2. Глинчикова Е.В. В прозрачности «Светлого Божества» (о возможности экзистенциальной интерпретации мистического опыта на примере произведения Н.Н. Трубникова «Зефи, светлое мое Божество, или после заседания (из записок покойного К.)») // Филология: научные исследования. 2013. № 1 (09). С. 43-48.

3. Жижек С. Чума фантазий. Х., 2012.

4. Лакан Ж. «Я» в теории Фрейда и в технике психоанализа (Семинар, Книга II (1954/55)). М., 2009.

5. Лэинг Р. Расколотое «я». СПб.,1995.

6. Сартр Ж.-П. Бытие и ничто. Опыт феноменологической онтологии. М., 2012.

\section{References (transliteration):}

1. Bad'yu Alen. Manifest filosofii / Sost. i per. s franc. V.E. Lapickogo. SPb.: Machina, 2003.

2. Glinchikova E.V. V prozrachnosti «Svetlogo Bozhestva» (o vozmozhnosti ekzistencial'noy interpretacii misticheskogo opyta na primere proizvedeniya N.N. Trubnikova «Zefi, svetloe moe Bozhestvo, ili posle zasedaniya (iz zapisok pokoynogo K.)») // Filologiya: nauchnye issledovaniya. 2013. № 1 (09). S. 43-48.

3. Zhizhek S. Chuma fantaziy. H., 2012.

4. Lakan Zh. «Ya» v teorii Freyda i v tehnike psihoanaliza (Seminar, Kniga II (1954/55)). M., 2009.

5. Leing R. Raskolotoe «ya». SPb., 1995.

6. Sartr Zh.-P. Bytie i nichto. Opyt fenomenologicheskoy ontologii. M., 2012. 